\title{
Q3 Effect of polyvinyl alcohol/nano-carbon colloid on the electrochemical performance of Q4 negative plates of lead acid battery
}

\author{
Q6 Q5 Jian Yin ${ }^{a}$, ZheQi Lin ${ }^{\text {a }}$, DeBo Liu ${ }^{\text {a }}$, Can Wang ${ }^{\text {a }}$, HaiBo Lin ${ }^{\text {a,b,c,*, WenLi Zhang }}$ a,b,d,* \\ $4 \quad$ a College of Chemistry, Jilin University, No.2699 Qianjin Street, Changchun 130012, China \\ b Jilin Kaiyu Electrochemical Energy Storage Technologies Development Co., Ltd., No. 5188 Guigu Street, Changchun 130012, China \\ ' Key Laboratory of Physics and Technology for Advanced Batteries of Ministry of Education, No. 2699 Qianjin Street, Changchun 130012, China \\ Q8 d Materials Science and Engineering, Physical Science and Engineering Division, King Abdullah University of Science and Technology (KAUST), Thuwal 23955-6900, Saudi Arabia
}

\section{A R T I C L E I N F O}

\section{Article history:}

Received 24 August 2018

Received in revised form 30 October 2018

Accepted 31 October 2018

Available online $\mathrm{xxxx}$

\section{Keywords:}

Partial state of charge

Renewable energy storage

Lead acid battery

Sulfation

Negative electrode

Hydrogen evolution reaction

\begin{abstract}
A B S T R A C T
Polyvinyl alcohol/nano-carbon colloid (PCC) was prepared through a simple physical mixture process. Both fully 20 charge-discharge and insufficient charge tests were carried out to demonstrate the positive effects of PCC on the 21 electrical storage capability of the negative electrode of lead acid battery. Cyclic voltammetry, steady polarization 22 and electrochemical impedance spectroscopy were used to characterize the influences of PCC on the electro- 23 chemical behaviors of negative electrode in the lead acid battery. Experiment results demonstrate that PCC has 24 positive effect on inhibiting $\mathrm{PbSO}_{4}$ growth and increasing the HER overpotential, thus the lead acid battery 25 with PCC shows the enhanced charge acceptance and stable discharge capacities under insufficient charge test. 26 This paper opens a new way for enhancing the performance of lead acid battery without changing the traditional 27 structure and design of lead acid battery.

(C) 2018 Elsevier B.V. All rights reserved. 29

\section{Introduction}

Lead acid battery ( $\mathrm{LAB}$ ) has been a reliable energy storage device for more than 150 years since Plante invented LAB in 1859 [1-3]. Due to its characteristics of safety, reliable performance and mature manufacture, lead acid battery has been applied in various applications, such as start, light and ignition (SLI) batteries for automobiles [4], uninterruptable power supply (UPS) [5], electric vehicles (especially for electric bicycles and tricycles) [6] and the storage of electricity generated by renewable energies or pulse power source in hybrid electrical vehicles [7,8]. The applications of LAB can be classified into four user modes: (i) Infrequent discharge for UPS, in which condition, LAB is under fully charged condition at most time of its service life; (ii) Frequent, shallow depth of discharge for SLI applications; (iii) Deep charge-discharge duty in electric vehicles; (iv) The forth situations, probably the most rapiddeveloping application of LAB in 21st century, are the applications of LAB under partial state of charge (PSoC) duty, such as battery module in hybrid electric vehicles and the grid-scale energy storage of electricity generated by renewable energy.

For grid-scale energy storage, LABs works as an electrical load when renewable energy generates extra energy. When the requirement of load can't be satisfied by renewable energy, LABs release power. In

* Corresponding authors at: College of Chemistry, Jilin University, No.2699 Qianjin Street, Changchun 130012, China.

E-mail addresses: lhb910@jlu.edu.cn (H. Lin), hiteur@163.com (W. Zhang). this case, LABs in renewable energy storage undergoes insufficient 62 charge, which is also called PSoC conditions $[9,10]$.

In PSoC duty, the negative active materials (NAM) of LAB faces 64 sulfation, namely, the electrochemically active $\mathrm{PbSO}_{4}$ with small particle 65 size grows into non-electrochemically active $\mathrm{PbSO}_{4}$ with large particle 66 size which can be hardly charged into its active state of sponge $\mathrm{Pb} 67$ [11]. The sulfation of negative electrode is one of the main problems 68 that shortens the cycle life of LAB, resulting in high electricity storage 69 cost of renewable energy storage. It's of great necessity to enhance the 70 service life of the negative electrode in LAB under PSoC operation. 71

Sulfation of negative electrode can be solved by inhibiting the 72 growth of $\mathrm{PbSO}_{4}$ particles. The addition of carbon materials into the 73 NAM could reduce the sulfation problem [12-20]. Although, carbon ma- 74 terials greatly enhances the electrical double layer capacitance and the 75 conductivity of negative plates at PSoC condition, the effect of carbon 76 materials on the electrochemical process is thought mainly due to alter- 77 ing of the active surface which serves as nucleation sites for the deposi- 78 tion of $\mathrm{Pb}$ in negative electrode $[15,16]$. This role of carbon materials is 79 just like the role of $\mathrm{BaSO}_{4}$, which reduces the particle size of $\mathrm{PbSO}_{4}$ by 80 severing as nucleation sites for the growth of $\mathrm{PbSO}_{4}$.

Despite of the positive effect of carbon materials, the production of 82 lead-carbon composite electrode is somewhat technically difficult due 83 to the change of the density of leady-oxide-based pastes, the lowered 84 over-potential of hydrogen evolution reaction (HER), the instability of 85 lead-carbon composite electrode and also the higher self-discharge 86 rate [21]. 

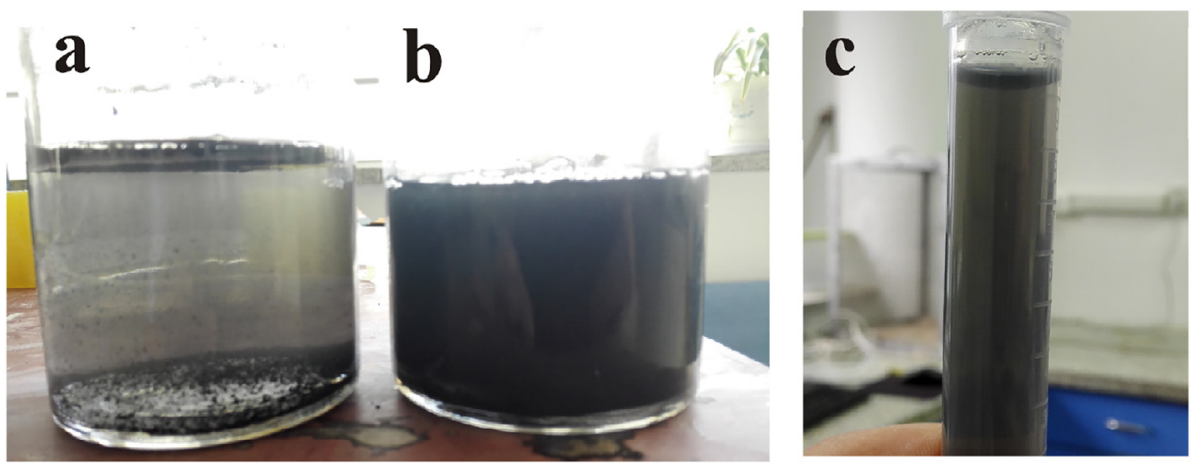

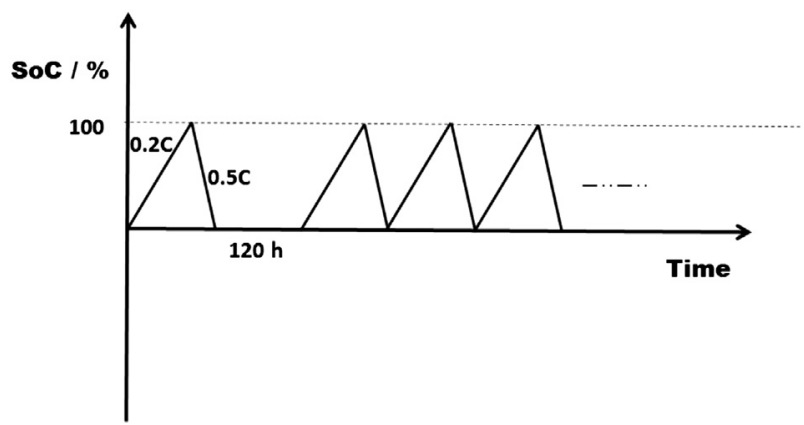

Fig. 2. Schematic diagram of the charge-discharge protocol for the energy storage stability under insufficient charge conditions.
Another way to reduce the sulfation of negative electrode is to ex- 88 plore sulfation inhibitor in the electrolyte of LAB. The addition of 89 sulfation inhibitor in the electrolyte is a facile method which can be 90 adopted in industrial production easily [22-28]. Wang et al. designed 91 a kind of polysiloxane-based gel electrolyte for LAB, the polysiloxane- 92 based gel electrode possesses higher HER over-potential than 93 traditional silica gel electrolyte [22]. Hence, the LAB based on the 94 polysiloxane-based gel electrolyte exhibits higher capacity. Based on 95 this case, the formation of gel electrolyte is very important for the 96 PSoC operation of LAB [23]. Polyaspartic acid (PASP) seems to be an ef- 97 fective additive in the sulfuric electrolyte, especially in gel-based- 98 electrolyte for LAB working under PSoC duty [24-26]. In 2006, Pavlov 99 et al. reported that PASP controls the crystallization process of $\mathrm{PbSO}_{4} 100$ and modifies the shape and size of $\mathrm{PbSO}_{4}$ crystals [24]. In 2012, Pavlov 101
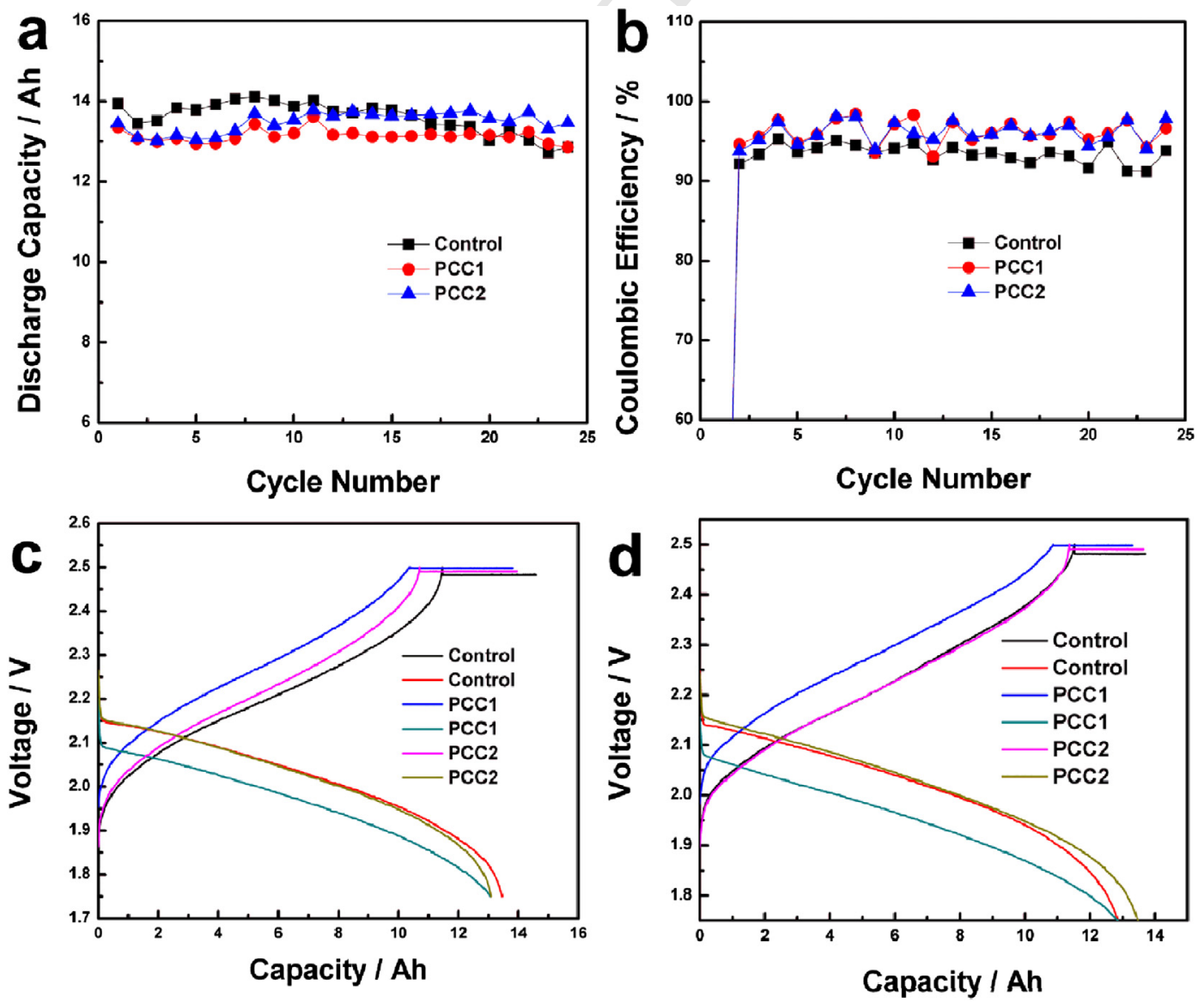

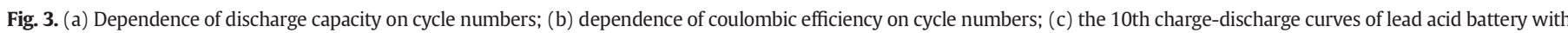
and without PCC; (d) the 24th charge-discharge curves of lead acid battery with and without PCC. 
further demonstrated the superior performance of PASP in electrolyte for a lead-carbon composite electrode [25]. In 2016, Tantavichet et al. discovered that the addition of $0.005(\mathrm{w} / \mathrm{v}) \%$ PASP in the gelled electrolyte could greatly enhance the performance of LAB in both $100 \%$ depth of discharge (DoD) and PSoC duty [26]. Notably, some other materials may be also suitable for both liquid electrolyte and gel-electrolyte. Deyab found the positive effect of L-serine on increasing the HER overpotential of negative electrode [27]. The electrolyte additives mentioned above reduce the particle size of $\mathrm{PbSO}_{4}$ [28]. Subsequently, the electrochemically active $\mathrm{PbSO}_{4}$ reduces polarization, which leads to low HER rate of negative electrodes and cyclic stability of LABs [16].

Since both organic additives and carbon materials [29-31] can be added to alter the electrochemical performance of negative electrode in LAB. In this paper, polyvinyl alcohol/nano-carbon colloid (PCC) was prepared through simple dissolution process. Experiment results demonstrate that PCC exhibits positive effect on suppressing the growth of $\mathrm{PbSO}_{4}$ and improving the cyclic stability of $\mathrm{LAB}$ under insufficient charge condition. This paper proposes a new way for enhancing the performance of lead acid battery without changing the structure and design of LAB.

\section{Experimental}

\subsection{Preparation of polyvinyl alcohol/nano-carbon colloid (PCC)}

To synthesize the polyvinyl alcohol/nano-carbon colloid (PCC) additives, first, a kind of water-soluble polymer, polyvinyl alcohol ( $20 \mathrm{~g})$, was dissolved in water $(500 \mathrm{~mL})$ at a fixed temperature of $95^{\circ} \mathrm{C}$ with a stir stirring for $2 \mathrm{~h}$, and then a kind of nano-sized carbon material, acetylene black $(1 \mathrm{~g})$, was added in the solution slowly with the help

of ultrasonic treatment for another $2 \mathrm{~h}$. PCC was collected and preserved 129 for use. As shown in Fig. 1, the nano-carbon precipitated in the water 130 (Fig. 1), while, PCC has good stability in water (Fig. 1b). The concentra- 131 tion of PCC in sulfuric acid electrolyte (s.g. $1.24 \mathrm{~g} \mathrm{~cm}^{-3}$ ) for container 132 formation or electrochemical test was 2 v\%, which is shown in Fig. 1c. 133 The PCC added in sulfuric electrolyte also shows good stability.

\subsection{Battery assembly and test}

A $2 \mathrm{~V}$ battery with commercial negative plates and positive plates 136 (obtained from Meineng group, Zhejiang province, China) was assem- 137 bled. The unit $2 \mathrm{~V}$ battery was composed of 7 positive plates and 8 neg- 138 ative plates. Each plate has a geometric area of $c a .7 \mathrm{~cm} \times 4 \mathrm{~cm} . \mathrm{H}_{2} \mathrm{SO}_{4} 139$ solution with specific gravity of $1.24 \mathrm{~g} \mathrm{~cm}^{-3}$ was used as electrolyte in 140 container formation process. The nominal 2 -h capacity $\left(C_{2}\right)$ of the assem- 141 bled battery was $12 \mathrm{Ah}$. The charge-discharge test of LAB was carried on a 142 battery tester (CT2001B, LANHE, China). The formation process was car- 143 ried out in a standard industrial formation process, which was applied in 144 our previous study [29]. After formation, the battery goes capacity test 145 with a constant charge current of $0.2 \mathrm{C}_{2}$ to $2.45 \mathrm{~V}$ and a constant charge 146 voltage of $2.45 \mathrm{~V}$ for $6 \mathrm{~h}$, the discharge current is $0.5 \mathrm{C}_{2}$ with a cut-off 147 voltage of $1.8 \mathrm{~V}$. The test of insufficient charge of lead acid battery was 148 shown in Fig. 2. After fully charged, the battery goes discharge and last 149 for $120 \mathrm{~h}$ ( 5 days) at discharged state, then the battery goes three 150 charge-discharge cycles, repeat the above process for 4 times.

\subsection{Physical and electrochemical characterization}

The morphologies of the negative plates were observed with a field 153 emission scan electron microscope (SEM) (SU8020, Hitachi, Japan). For 154
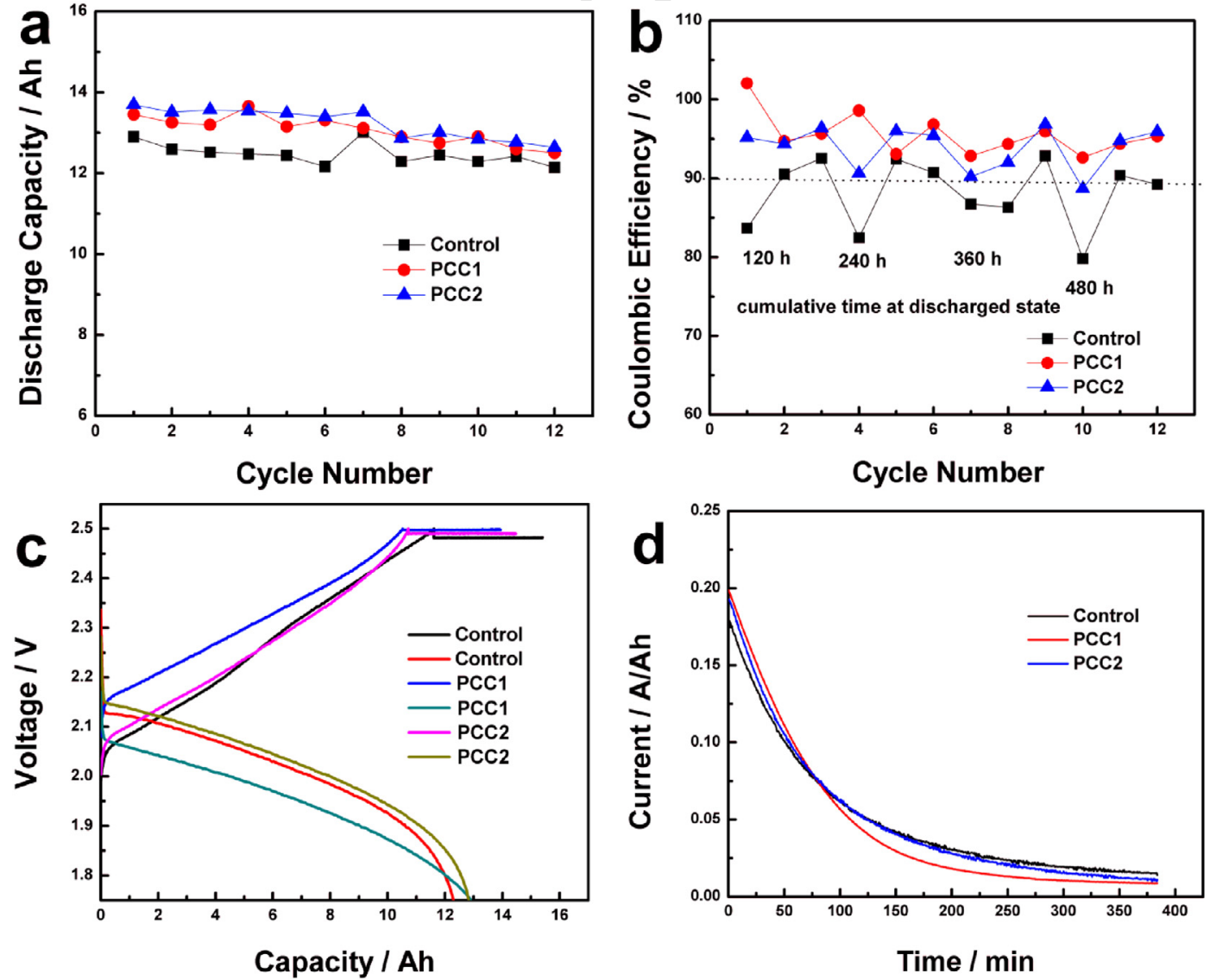

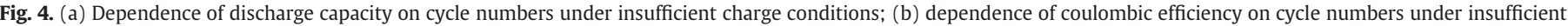

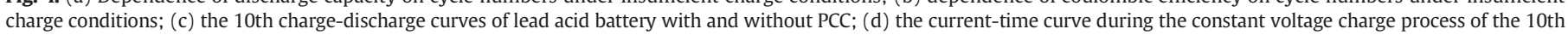
charge-discharge. 
three-electrode electrochemical investigations, a pure lead electrode with geometric area of $2 \mathrm{~cm} \times 2 \mathrm{~cm}$ was applied. $\mathrm{H}_{2} \mathrm{SO}_{4}$ with specific gravity of 1.28 was used as electrolyte. The pretreatment of lead electrode was described in our previous work [16]. Cyclic voltammetry, steady polarization and electrochemical impedance spectroscopy (EIS) were tested on an electrochemical work station (Parstat 2273, Ametek, USA). Steady polarization was test with chronoamperometry method and the current response was collected after $1200 \mathrm{~s}$ when a certain potential was set. The EIS results were simulated via Zsimpwin software. In the three electrode measurement, all the potentials were quoted with respect to a mercurous sulfate electrode (MSE) $\left(\mathrm{Hg} / \mathrm{Hg}_{2} \mathrm{SO}_{4} / \mathrm{K}_{2} \mathrm{SO}_{4}\right.$ (saturated), $0.65 \mathrm{~V} v$ s. SHE).

\section{Results and discussions}

To demonstrate the positive effects of PCC towards lead acid battery, two parallel experiments (PCC1 and PCC2) were carried out. As shown in Fig. 3a, LAB with PCC added in the electrolyte has a relatively smaller capacity than the control battery at initial 10 cycles. However, higher capacity of LAB with PCC was observed from 18 to 24 cycles. The coulombic efficiency of LAB usually is higher than $90 \%$ due to the high HER overpotential on $\mathrm{Pb}$ electrode and high oxygen evolution overpotential on $\mathrm{PbO}_{2}$ electrode. The coulombic efficiency of the control battery and LAB with PCC was displayed in Fig. 3b. Owing to the addition of PCC in the electrolyte in LAB, the LAB with PCC has a much higher coulombic efficiency than the control battery, which can be seen from the 10th (Fig. 3c) and 24th (Fig. 3d) charge-discharge curves.

As shown in Fig. 4a, the capacity of the control battery is relatively lower than the LAB with PCC within the 12 cycles under insufficient charge condition. Great difference has been seen in the coulombic efficiency (Fig. 4b), the LAB with PCC has a much higher coulombic
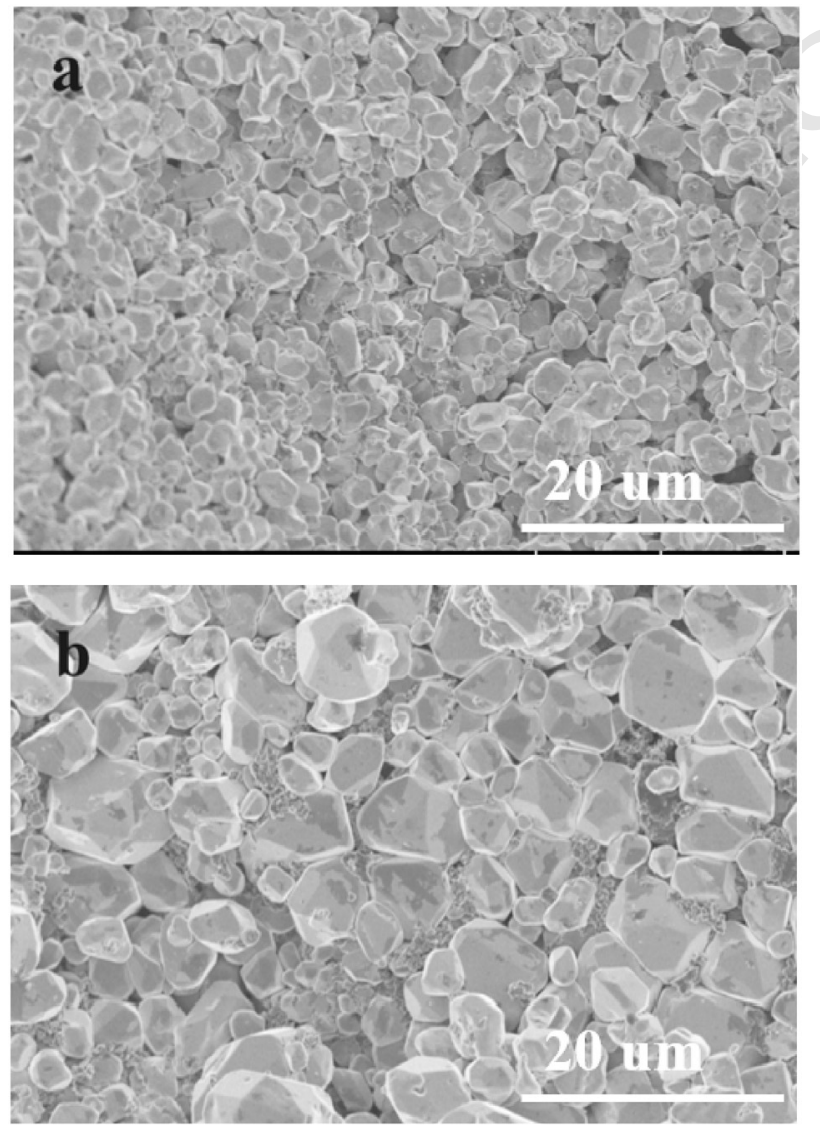

Fig. 5. SEM images of the surface of negative plate after insufficient charge test (a) with PCC and (b) without PCC. efficiency than the control battery. The control battery only has a cou- 184 lombic efficiency of $83.65 \%$ after exposed at discharged condition for 185 $120 \mathrm{~h}$. With the accumulation of time at discharged condition for 186 $480 \mathrm{~h}$, the control battery only has a coulombic efficiency of $79.81 \%, 187$ much lower than LAB with PCC (90\%-95\%). This result is due to the 188 lowered charge acceptance of lead negative electrode, since sulfation 189 of negative electrode occurs when LAB was exposed at discharged con- 190 dition for long time [9]. The subsequent reaction is the HER reaction on 191 $\mathrm{Pb}$ negative electrode, which decreases the coulombic efficiency. Al- 192 though the coulombic efficiency of LAB with PCC lowers after $120 \mathrm{~h}$ ex- 193 posed at discharged condition, the coulombic efficiency of LAB with PCC 194 was much higher than the control battery. Within 12 charge-discharge 195 cycles, LAB with PCC always has a coulombic efficiency above 90\%. The 196 above results demonstrated that, PCC can improve the charge accep- 197 tance of negative electrode under insufficient charge conditions. The 198 charge-discharge curves of LAB with PCC and control battery (Fig. 4c) 199 reveals the much better charge acceptance of LAB with PCC than the 200 control battery. Current-time curve at the constant voltage charge pro- 201 cess reveals that the hydrogen evolution rate of LAB with PCC was lower 202 than the control battery (Fig. 4d). Namely, the side-reaction of HER was 203 lowered by adding PCC in electrolyte, which is the reason for the en- 204 hanced charge acceptance of LAB with PCC additive. 205

Large $\mathrm{PbSO}_{4}$ particle size will make Pb electrode less electrochemi- 206 cally active, hence the HER on the sulfated negative electrode will be 207 more preferential than the non-sulfated one. The preferential HER on 208 sulfated lead negative electrode is the reason for the lowered coulombic 209 efficiency. The sulfation of negative electrode will thus result in the sub- 210 sequent loss of water and the failure of LAB to store electricity. SEM was 211 used to observe the $\mathrm{PbSO}_{4}$ accumulated on the surface of the negative 212
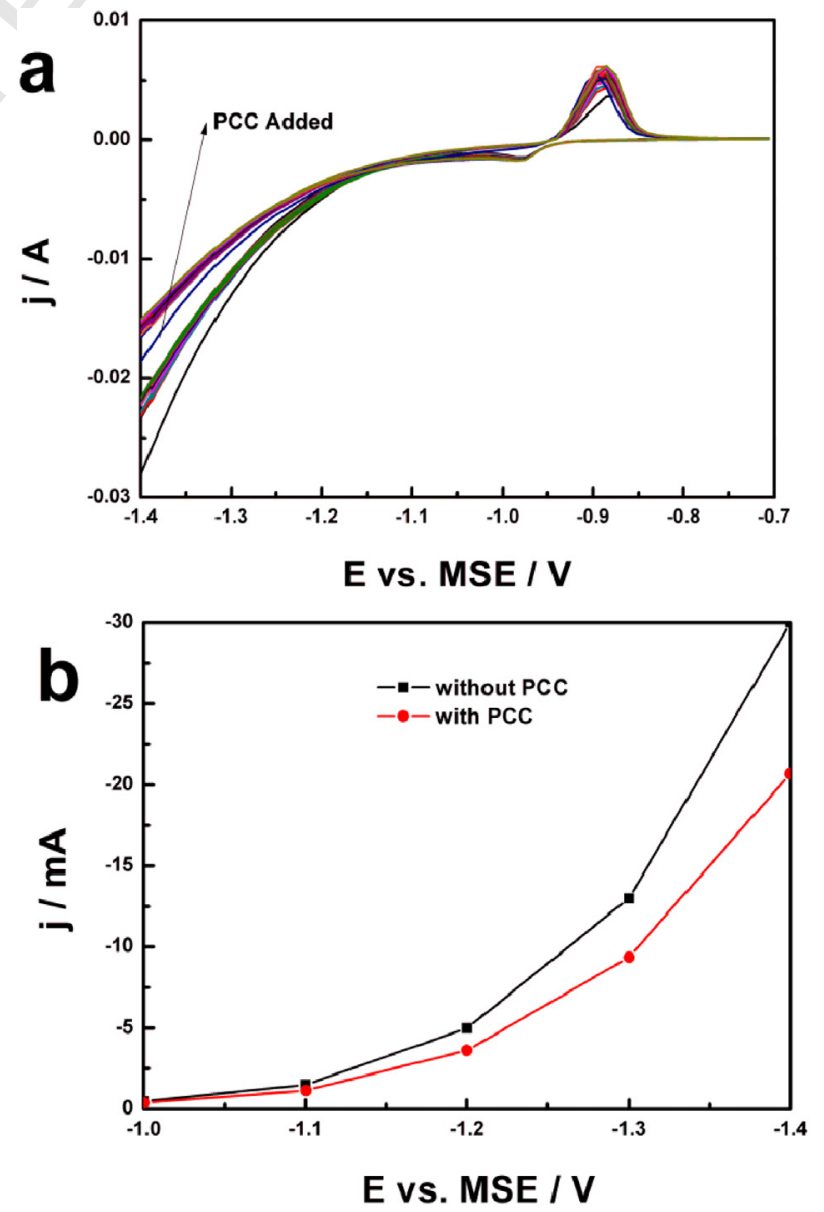

Fig. 6. (a) Cyclic voltammograms of lead with continuous test before and after the addition of PCC; (b) steady polarization curve of lead with and without PCC added in electrolyte. 
plates of LAB, as can be seen, the LAB with PCC in electrolytes has smaller $\mathrm{PbSO}_{4}$ particle size (Fig. 5a) accumulated on the surface of negative plates of LAB than the control battery (Fig. 5b). The PCC used in electrolyte reduces the particle size of $\mathrm{PbSO}_{4}$ effectively.

Eelectrochemical experiments were carried out to study the influence of PCC on the electrochemical behavior of Pb electrode. Cyclic voltammograms from $-1.4 \mathrm{~V}$ to $-0.7 \mathrm{~V}$ (Fig. 6a) were carried out to study the electrochemical behavior of $\mathrm{Pb}$ in $5 \mathrm{M} \mathrm{H}_{2} \mathrm{SO}_{4}$, the oxidation peak tends to increase due to the activation of surface. After the activation of $\mathrm{Pb}$ surface, the oxidation peak tends to be steady. The nano-carbon materials in the colloids do not show clear effect on the reversibility of $\mathrm{Pb} / \mathrm{PbSO}_{4}$ redox couple, probably because of the unabsorbed state of

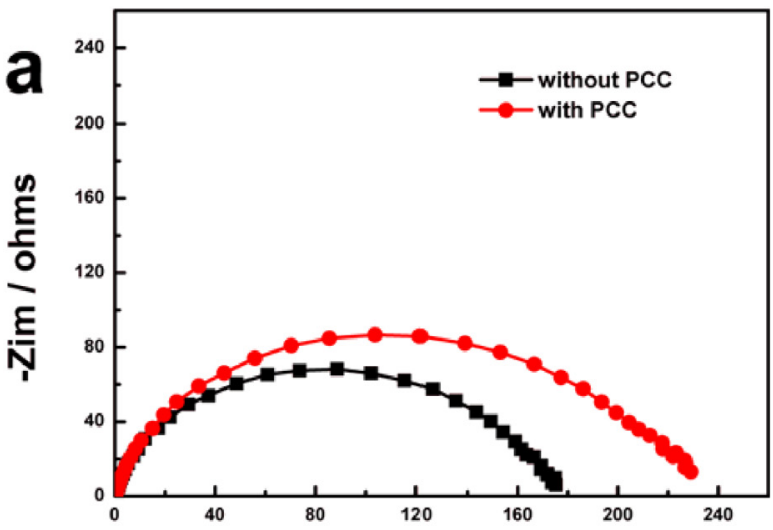

Zre / ohms
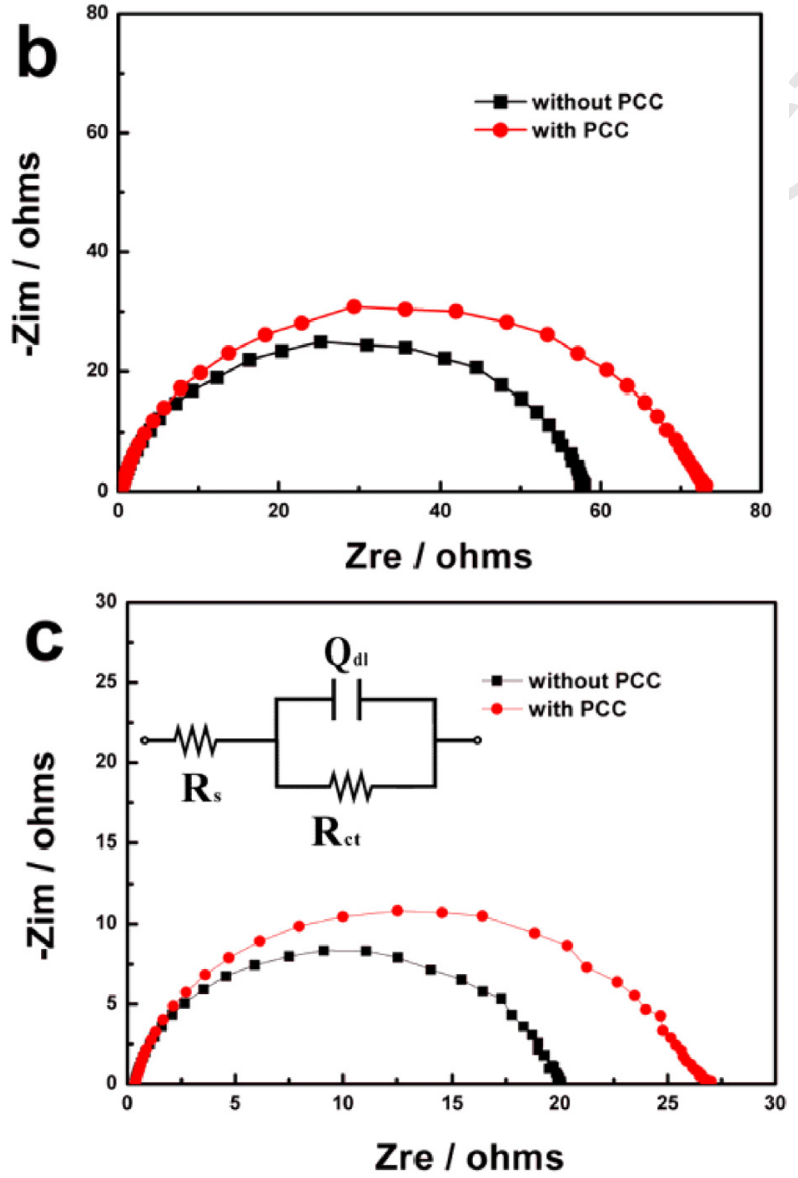

Fig. 7. Electrochemical impedance spectra (Nyquist plot) measured on Pb electrode with PCC or without PCC in electrolyte at (a) $-1.0 \mathrm{~V}$, (b) $-1.1 \mathrm{~V},(\mathrm{c})-1.2 \mathrm{~V}$ vs. MSE, respectively. The inset of $(\mathrm{c})$ is the equivalent circuit of $\mathrm{Pb}$ electrode.
Table 1

Simulated values of each element in the equivalent circuit of Pb electrode with or without $t 1.2$ the addition of PCC.

\begin{tabular}{|c|c|c|c|c|c|c|}
\hline Potential & Electrolyte & $\mathrm{R}_{\mathrm{s}}$ & $\mathrm{Q}_{\mathrm{dl}}$ & $\mathrm{n}$ & $\mathrm{R}_{\mathrm{ct}}$ & $\chi^{2}$ \\
\hline V & & $\Omega$ & $\Omega^{-1} s^{n}$ & - & $\Omega$ & - \\
\hline \multirow[t]{2}{*}{-1.0} & Without & 0.336 & $1.674 \times 10^{-4}$ & 0.8961 & 169.3 & $2.64 \times 10^{-3}$ \\
\hline & With PCC & 0.341 & $1.471 \times 10^{-4}$ & 0.8924 & 219.2 & $4.54 \times 10^{-3}$ \\
\hline \multirow[t]{2}{*}{-1.1} & Without & 0.348 & $1.007 \times 10^{-4}$ & 0.9200 & 57.15 & $3.19 \times 10^{-3}$ \\
\hline & With PCC & 0.356 & $9.081 \times 10^{-5}$ & 0.9155 & 71.51 & $2.92 \times 10^{-3}$ \\
\hline \multirow[t]{2}{*}{-1.2} & Without & 0.387 & $6.585 \times 10^{-5}$ & 0.9455 & 19.22 & $1.34 \times 10^{-2}$ \\
\hline & With PCC & 0.373 & $7.278 \times 10^{-5}$ & 0.9226 & 25.76 & $4.49 \times 10^{-3}$ \\
\hline
\end{tabular}

nano-carbon materials in the electrochemical test cell. However, in a 225 compressed $L A B$, especially a valve-regulated $L A B$, the nano-carbon ma- 226 terials absorbs on the surface of negative plate, because the internal ox- 227 ygen combination reaction pushes the nano-carbon onto the surface of 228 $\mathrm{Pb}$ plates. Nano-carbon on the surface of negative plates thus can work 229 as the electrochemical active sites for the deposition of $\mathrm{Pb}$ in the charge 230 process [32]. The hydrogen evolution behavior has been greatly influ- 231 enced by the addition of PCC in electrolyte. The Pb electrode has a higher 232 overpotential of HER, which is caused by the polyvinyl alcohol in PCC. 233 The HER rate has been lowered by the addition of PCC which can be 234 seen from the lower current response after the addition of PCC in elec- 235 trolyte. Steady polarization (Fig. 6b) also demonstrated the lowered 236 HER rate after the addition of PCC in electrolyte. The lowered HER rate 237 of Pb electrode with PCC added in the electrolyte will endow LAB a 238 high charge acceptance.

Electrochemical impedance spectroscopy (EIS) (Fig. 7) was used to 240 study the electrode/electrolyte interface of $\mathrm{Pb} / \mathrm{H}_{2} \mathrm{SO}_{4}$ system. The as 241 prepared $\mathrm{Pb}$ electrode was polarized at $-1.2 \mathrm{~V}$ for $20 \mathrm{~min}$ to eliminate 242 the oxides on the surface of Pb. The EIS was measured at $-1.0 \mathrm{~V}, 243$ $-1.1 \mathrm{~V}$ and $-1.2 \mathrm{~V}$ respectively. Clear tendency can be observed that 244 the impedance of Pb electrode with PCC in electrolyte was much higher 245 than the Pb without PCC in electrolyte. The Nyquist plot shows a charge- 246 transfer dominated behavior. Hence a classical R(QR) equivalent circuit 247 was used to simulate the electrical behavior. In the equivalent circuit, $R_{S} 248$ stands for the ohm resistance, $Q_{\mathrm{dl}}$ represents the non-ideal electrical 249 double layer capacitor behavior and $\mathrm{R}_{\mathrm{ct}}$ is the charge transfer resistance 250 of HER on Pb electrode. The simulated results of the electrical elements 251 are listed in Table 1. As shown in Table 1, the clear tendency was seen 252 that the $\mathrm{R}_{\mathrm{ct}}$ of Pb with PCC in electrolyte was much higher than Pb elec- 253 trode without PCC. As an example, at $-1.0 \mathrm{~V}$ the charge transfer resis- 254 tance of Pb with PCC is $219.2 \Omega$, which is higher than Pb without PCC 255 in electrolyte $(169.3 \Omega)$. At $-1.2 \mathrm{~V}$, the charge transfer resistance of 256 $\mathrm{Pb}$ with PCC is $25.76 \Omega$, which is higher than Pb without PCC in electro- 257 lyte (19.22 $\Omega$ ). The increased charge transfer resistance of Pb electrode 258 with PCC in electrolyte demonstrated the HER inhibitor effect of PCC on 259 $\mathrm{Pb}$ electrode during the charge process of LAB.

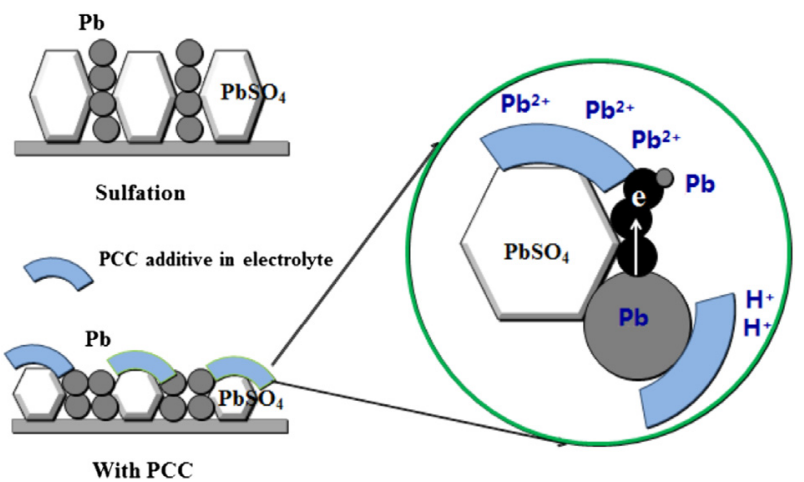

Fig. 8. Schematic diagram of the mechanism of PCC on Pb electrode. 


\section{Conclusion}

In summary, the PCC added in the electrolyte of LAB has the following function (shown as schematic diagram shown in Fig. 8): (i) PCC can reduce the particle size of $\mathrm{PbSO}_{4}$ on $\mathrm{Pb}$ electrode when $\mathrm{Pb}$ electrode is under insufficient charge condition, the reduced particle size of $\mathrm{PbSO}_{4}$ makes it more electrochemically active; (ii) polyvinyl alcohol in PCC works as $\mathrm{HER}$ inhibitor altering the $\mathrm{Pb} / \mathrm{HSO}_{4}$ interface, and thus inhibiting the HER rate on Pb surface; (iii) carbon in the PCC may absorbed on the surface on $\mathrm{Pb}$ electrode, thus increasing the electrochemical active surface during the charge process of $\mathrm{Pb} / \mathrm{PbSO}_{4}$ electrode. Since polyvinyl alcohol and acetylene black are very common, and the preparation of PCC is rather simple, PCC holds great potential to be used in the present lead acid battery industry.

\section{Acknowledgements}

The research group acknowledges the financial support provided by National Natural Science Foundation of China (No. 21573093), the National Key Research and Development Program (No. 2017YFB0307501), Guangdong Innovative and Entrepreneurial Research Team Program (No. 2013C092) and the Graduate Innovation Fund of Jilin University (No. 2015141).

\section{References}

[1] D. Pavlov, Lead-Acid Batteries: Science and Technology, Elsevier, Amsterdam, 2011.

[2] D.A.J. Rand, P.T. Moseley, J. Garche, C.D. Parker, Valve-regulated Lead Acid Batteries, Elsevier, Amsterdam, 2004.

[3] J. Jung, L. Zhang, J. Zhang, Lead-acid Battery Technologies: Fundamentals, Materials, and Applications, CRC press, Boca Raton, 2015.

[4] R. Marom, B. Ziv, A. Banerjee, B. Cahana, S. Luski, D. Aurbach, Enhanced performance of starter lighting ignition type lead-acid batteries with carbon nanotubes as an additive to the active mass, J. Power Sources 296 (2015) 78-85.

[5] B. Culpin, D.A.J. Rand, Failure modes of lead/acid batteries, J. Power Sources 36 (1991) 415-438.

[6] J.X. Weinert, A.F. Burke, X. Wei, Lead-acid and lithium-ion batteries for the Chinese electric bike market and implications on future technology advancement, J. Power Sources 172 (2007) 938-945.

[7] Y. Chang, X. Mao, Y. Zhao, S. Feng, H. Chen, D. Finlow, Lead-acid battery use in the development of renewable energy systems in China, J. Power Sources 191 (2009) 167-183.

[8] W. Zhang, H. Lin, H. Kong, H. Lu, Z. Yang, T. Liu, Preparation and characterization of lead dioxide electrode with three-dimensional porous titanium substrate for electrochemical energy storage, Electrochim. Acta 139 (2014) 209-216.

[9] I.K. Gibson, K. Peters, Sulphation in discharged lead-acid batteries, J. Power Sources 8 (1982) 143-157.

[10] R.H. Newnham, W.G.A. Baldsing, Benefits of partial-state-of-charge operation in remote-area power-supply systems, J. Power Sources 107 (2002) 273-279.

[11] L.T. Lam, N.P. Haigh, C.G. Phyland, A.J. Urban, Failure mode of valve-regulated leadacid batteries under high-rate partial-state-of-charge operation, J. Power Sources 133 (2004) 126-134.

[12] B.B. McKeon, J. Furukawa, S. Fenstermacher, Advanced lead-acid batteries and the development of grid-scale energy storage systems, Proc. IEEE 102 (2014) 951-963.
[13] R. Shapira, G.D. Nessim, T. Zimrin, D. Aurbach, Towards promising electrochemical 310 technology for load leveling applications: extending cycle life of lead acid batteries 311 by the use of carbon nano-tubes (CNTs), Energy Environ. Sci. 6 (2013) 587-594. 312

[14] M. Saravanan, P. Sennu, M. Ganesan, S. Ambalavanan, Multi-walled carbon nano- 313 tubes percolation network enhanced the performance of negative electrode for 314 lead-acid battery, J. Electrochem. Soc. 160 (2013) A70-A76. 315

[15] D. Pavlov, T. Rogachev, P. Nikolov, G. Petkova, Mechanism of action of electrochem- 316 ically active carbons on the processes that take place at the negative plates of lead- 317 acid batteries, J. Power Sources 191 (2009) 58-75. 318

[16] W. Zhang, H. Lin, H. Lu, D. Liu, J. Yin, Z. Lin, On the electrochemical origin of the en- 319 hanced charge acceptance of lead-carbon electrode, J. Mater. Chem. A 3 (2015) 320 4399-4404.

[17] S. Logeshkumar, R. Manoharan, Influence of some nanostructured materials addi- 322 tives on the performance of lead acid battery negative electrodes, Electrochim. 323 Acta 144 (2014) 147-153.

[18] S.W. Swogger, P. Everill, D.P. Dubey, N. Sugumaran, Discrete carbon nanotubes in- 325 crease lead acid battery charge acceptance and performance, J. Power Sources 261326 (2014) 55-63.

[19] B. Hong, L. Jiang, H. Xue, F. Liu, M. Jia, J. Li, Y. Liu, Characterization of nano-lead- 328 doped active carbon and its application in lead-acid battery, J. Power Sources 270329 (2014) 332-341.

[20] M. Saravanan, M. Ganesan, S. Ambalavanan, An in situ generated carbon as inte- 331 grated conductive additive for hierarchical negative plate of lead-acid battery, 332 J. Power Sources 251 (2014) 20-29. 333

[21] B. Hariprakash, S.A. Gaffoor, A.K. Shukla, Lead-acid batteries for partial-state-of- 334 charge applications, J. Power Sources 191 (2009) 149-153.

[22] Z. Tang, J. Wang, X. Mao, H. Shao, Q. Chen, Z. Xu, J. Zhang, Investigation and applica- 336 tion of polysiloxane-based gel electrolyte in valve-regulated lead-acid battery, 337 J. Power Sources 168 (2007) 49-57.

[23] J.C. Hernandez, M.L. Soria, M. Gonzalez, E. Garcia-Quismondo, A. Munoz, F. Trinidad, 339 Studies on electrolyte formulations to improve life of lead acid batteries working 340 under partial state of charge conditions, J. Power Sources 162 (2006) 851-863. 341

[24] G. Petkova, P. Nikolov, D. Pavlov, Influence of polymer additive on the performance 342 of lead-acid battery negative plates, J. Power Sources 158 (2006) 841-845. 343

[25] D. Pavlov, P. Nikolov, Lead-carbon electrode with inhibitor of sulfation for lead-acid 344 batteries operating in the HRPSoC duty, J. Electrochem. Soc. 159 (2012) 345 A1215-A1225.

[26] P. Tundorn, O. Chailapakul, N. Tantavichet, Polyaspartate as a gelled electrolyte ad- 347 ditive to improve the performance of the gel valve-regulated lead-acid batteries 348 under $100 \%$ depth of discharge and partial-state-of charge conditions, J. Solid State 349 Electrochem. 20 (2016) 801-811.

[27] M.A. Deyab, Hydrogen evolution inhibition by L-serine at the negative electrode of a 351 lead-acid battery, RSC Adv. 5 (2015) 41365.

[28] R.K. Ghavami, F. Kameli, A. Shirojan, A. Azizi, Effects of surfactants on sulfation of 353 negative active material in lead acid battery under PSOC condition, J. Energy Storage 354 7 (2016) 121-130.

[29] W.L. Zhang, J. Yin, Z.Q. Lin, J. Shi, C. Wang, D.B. Liu, Y. Wang, J.P. Bao, H.B. Lin, Lead- 356 carbon electrode designed for renewable energy storage with superior performance 357 in partial state of charge operation, J. Power Sources 342 (2017) 183-191. 358

[30] J. Yin, N. Lin, W. Zhang, Z. Lin, Z. Zhang, Y. Wang J. Shi, J. Bao, H. Lin, Highly reversible 359 lead-carbon battery anode with lead grafting on the carbon surface, J. Energy Chem. 360 27 (2018) 1674-1683.

[31] J. Yin, N. Lin, Z. Lin, Y. Wang, J. Shi, J. Bao, H. Lin, W. Zhang, Optimized lead carbon 362 composite for enhancing the performance of lead-carbon battery under HRPSoC op- 363 eration, J. Electroanal. Chem. (2018) https://doi.org/10.1016/j.jelechem.2018.10. 364 022.

[32] D. Pavlov, P. Nikolov, T. Rogachev, Influence of carbons on the structure of the neg- 366 ative active material of lead-acid batteries and on battery performance, J. Power 367 Sources 196 (2011) 5155-5167. 